\title{
Dental caries experience and associated factors in 12-year-old-children: a population based-study
}

\author{
Arella Cristina Muniz BRITO(a) iD \\ Isis Morais BEZERRA(a) iD \\ Denise de Fátima Barros \\ CAVALCANTE(b) ID \\ Antônio Carlos PEREIRA(b) \\ Vladen VIEIRA ${ }^{(c)}$ \\ Maria Fernanda MONTEZUMA ${ }^{(c)}$ \\ Edson Hilan Gomes de \\ LUCENA $^{\text {(d) }}$ \\ Yuri Wanderley CAVALCANTI(d) \\ Leopoldina de Fátima Dantas de \\ ALMEIDA $^{(d)}$ iD \\ (a) Universidade Federal da Paraíba - UFPB, \\ Postgraduate Program in Dentistry, João \\ Pessoa, PB, Brazil. \\ (b) Universidade Estadual de Campinas - \\ Unicamp, Piracicaba Dental School, Department \\ of Social Dentistry, Piracicaba, SP, Brazil. \\ (c) Private Orthodontics Office, São Paulo, \\ SP, Brazil. \\ (d) Universidade Federal da Paraíba - UFPB, \\ Clinical and Social Dentistry Department, \\ João Pessoa, PB, Brazil.
}

Declaration of Interests: The authors certify that they have no commercial or associative interest that represents a conflict of interest in connection with the manuscript.

\section{Corresponding Author:}

Leopoldina de Fátima Dantas de Almeida E-mail: leopoldinalmeida@hotmail.com

https://doi.org/10.1590/1807-3107bor-2020.vol34.0010
Abstract: Relevant public policies in oral health have been implemented in Brazil since 2004. Changes in the epidemiological status of dental caries are expected, mainly in the child population. This study aimed to assess the dental caries experience and associated factors among 12-year-old children in the state of São Paulo, Brazil. A cross-sectional population-based study was conducted with data obtained from 415 cities, including a total of 26,325 schoolchildren who were included by the double-stage cluster technique, by lot and by systematic sampling. The statistical model included data from the São Paulo Oral Health Survey (SBSP 2015), the Human Development Index (HDI) and the Social Vulnerability Index (SVI). A theoretical-conceptual model categorized the variables into three blocks, namely, contextual (HDI, SVI, region of residence and fluoridation of water), individual (sex and ethnicity) and periodontal conditions (gingival bleeding, dental calculus and the presence of periodontal pockets), for association with the experience of caries (DMFT). Statistically significant associations were verified by hierarchical multivariate logistic $(\mathrm{L})$ and Poisson $(\mathrm{P})$ regression analyses $(\mathrm{p}<0.05)$. The results showed that $57.7 \%$ of 12 -year-old children had caries experience. Factors that determined a greater prevalence of dental caries in both models were nonwhite ethnicity $\left(\mathrm{OR}_{\mathrm{L}}=1.113\right.$, $\left.\mathrm{OR}_{\mathrm{P}}=1.154\right)$ and the presence of gingival bleeding $\left(\mathrm{OR}_{\mathrm{L}}=1.204\right.$, $\left.\mathrm{OR}_{\mathrm{P}}=1.255\right)$. Male children $\left(\mathrm{OR}_{\mathrm{L}}=0.920 \mathrm{OR}_{\mathrm{P}}=0.859\right)$ and higher HDI $\left.\left(\mathrm{OR}_{\mathrm{L}}=0.022\right), \mathrm{OR}_{\mathrm{P}}=0.040\right)$ were associated with a lower prevalence of dental caries experience. Water fluoridation was associated with a lower DMFT index $\left(\mathrm{OR}_{\mathrm{P}}=0.766\right)$. Dental caries experience is still associated with social inequalities at different levels. Policymakers should direct interventions towards reducing inequalities and the prevalence of dental caries among 12-year-old children.

Keywords: Dental Health Surveys; Human Development; Dental Caries; Healthcare Disparities.

\section{Introduction}

Dental caries prevalence among 12-year-old children has decreased Submitted: August 8, 2019 Last revision: January 13, 2020 over the last several decades in Brazil. ${ }^{1,2}$ However, the prevalence of untreated dental caries is still considered high ${ }^{3}$ and is still higher 
than the rates observed in developed countries. ${ }^{4}$ A high prevalence of dental caries may impact children's quality of life, their reports of pain and their absences from school. ${ }^{4}$ A more accurate analysis of dental caries prevalence and its associated factors is necessary considering the continental dimensions and socioeconomic differences among the different regions of Brazil. Epidemiological studies may therefore contribute to the improved planning of health actions and services.

Relevant oral public health and other affirmative policies to reduce social inequalities have been implemented in Brazil since 2004. ${ }^{5}$ The Smiling Brazil Program has increased the financial resources and staff available to provide oral health care within the public health system. ${ }^{5}$ The epidemiology of dental caries in Brazil was reported in two national epidemiological surveys conducted in 2003 and 2010, which demonstrated an improvement in epidemiological data. ${ }^{1,2,3}$ In addition, epidemiological surveys have demonstrated the impact of inequalities on the prevalence of dental caries in Brazil. ${ }^{3,6,7}$ Although the epidemiology of dental caries has improved, factors associated with dental caries experience among 12-year-old children did not change during the period between 2003 and 2010.6,7

Multivariate and multilevel statistical models have indeed investigated factors associated with dental caries prevalence in the 12-year-old population. $6.7,7,9$ Dental caries experience in this age group has been determined worldwide as a parameter for evaluating permanent dentition, in addition to enabling the early identification of possible risk factors. ${ }^{10}$ Factors related to the prevalence of dental caries go beyond biological determinants and can include socioeconomic, contextual and individual variables. ${ }^{8,11}$ Based on the aforementioned evidence, it is necessary to evaluate the factors associated with dental caries among children who were exposed to the effects of the national public oral health policy and then determine whether changes in the associated factors have occurred.

An analysis relative to the population of the state of São Paulo may illustrate how complex the distribution of dental caries is and reveal the main associated factors. The state of São Paulo is considered the most populous federal unit in the country, with a Human Development Index (HDI) higher than that of European countries such as Portugal and Belgium. Although HDI is a sign of development, social inequality and social vulnerability are not necessarily correlated. Well-developed regions in Brazil, including the state of São Paulo, can markedly be composed of unequal and vulnerable populations. Based on this premise, the evaluation of contextual determinants other than the HDI is necessary to understand the prevalence and distribution of dental caries.

Although it is not possible to determine a direct causal relationship, the literature has reported that contextual factors such as the Human Development Index (HDI) and the Social Vulnerability Index (SVI) can influence the prevalence of dental caries. ${ }^{12,13} \mathrm{~A}$ previous study identified that the HDI increase was related to the improvement in oral health conditions among 12-year-old children in Brazil, ${ }^{8}$ whereas SVI influenced the experience of dental caries in adolescents..$^{12}$ Few studies, if any, have evaluated the impact of SVI on dental caries prevalence among 12-year-old children. The effect of other factors, such as access to fluoridated water, ${ }^{14}$ region of residence (urban or rural), ${ }^{15,16}$ sex, ${ }^{7,8}$ ethnicity ${ }^{7,17,18}$ and periodontal conditions ${ }^{19}$ may be assessed by means of a hierarchical multivariate regression model in addition to the HDI and SVI. This information could lend greater credibility and rationality to oral health actions proposed by public managers. In addition, greater clarification of the factors associated with dental caries could improve children's quality of life and reduce their absences from school. ${ }^{12,13}$

Although the literature has reported some data on multivariate and multilevel analyses, 7,8 more robust and up-to-date data are necessary to evaluate the impact of public policies and drive future interventions. The oral health survey in the state of São Paulo was a population-based study representative of the most populous region of Brazil, including over 25 thousand children. Thus, the aim of this study was to verify the association between dental caries experience and contextual, individual and periodontal factors in 12-year-old children based on this survey. 


\section{Methodology}

\section{Sample size and data collection}

The present study was an analytical cross-sectional study using secondary data from the state of São Paulo Oral Health Survey (SBSP 2015), ${ }^{20}$ conducted in 2015 with schoolchildren at the age of 12 , and the survey report has previously been published. ${ }^{20}$

The SBSP 2015, a study conducted in the state of São Paulo, Brazil, included 415 municipalities out of a total of 645 (64.34\%), representing 12-year-old children from public primary schools. Sample calculation followed the WHO recommendations (1997), in which a minimum of 40 schools per sample unit (municipalities) were included. The main sampling unit was the municipality, while the second sampling unit was the school. Municipalities were randomly selected within each macroregion, and schools were randomly selected within each municipality. The final sample consisted of approximately $5 \%$ of the estimated population for the state of São Paulo. A design effect of 2.0 was assumed using the double-stage conglomerate technique, which resulted in a minimum of 80 children per municipality. An additional $20 \%$ of estimated loss was added to ultimately round off the value to 100 children per municipality. Twenty schools were selected in each municipality by means of systematic sampling. In cases of municipalities that had fewer than 20 schools, all schools became eligible. Children were selected by means of systematic sampling after weighting the number of eligible children within each school. The Metropolitan Region of São Paulo, including the municipality of São Paulo, as well as the municipalities included in the region of Bauru and Taubaté, did not participate in the survey. The final sample consisted of 27,305 individuals.

A total of 315 work teams contributed to data collection in this study. Each team was composed of a dentist who performed the oral exam and administered the questionnaires and an oral health assistant who took notes on the information provided during the exam. The teams were trained in a 16-hour workshop, in which the research team discussed the steps of the study and the assignments of participants, in addition to establishing an acceptable uniformity relative to codes and criteria. The examiner calibration process lasted for at least 24 hours. A gold-standard examiner conducted the training and calibration processes of the teams to achieve overall agreement. An acceptable level of interrater agreement statistics (kappa $=0.87)$ was achieved.

\section{Ethical aspects}

The state of São Paulo Oral Health Survey was approved by the Research Ethics Committee of the Piracicaba Dental School of the University of Campinas $\left(n^{\circ}\right.$ 1.211.025; CAAE 467882 15.9.0000.5418). A signed term of free and informed consent was obtained from the legal guardians of each of the children involved in the primary study. After completion of the survey, the dataset was published and made publicly available on the SBSP-2015 research platform at https://w2.fop.unicamp.br/sbsp2015. Analyses for the present study were based on secondary data.

\section{Study variables}

Demographic data used for analyses included sex, ethnicity, region of residence and water fluoridation. Sex was classified as male or female, the region of residence was defined as rural or urban, and access to fluoridated water was established as with or without access. Yellow, indigenous, black and brown ethnicities were included in a single category, classified as "nonwhite" ethnicity. ${ }^{12}$ The decay-missing-filled teeth index (DMF-T) was used to report dental caries experience in permanent dentition. The DMF-T was used as both a continuous and categorical variable. DMF-T values were dichotomized as caries experience (DMFT-D $\geq 1$ ) or lack of dental caries experience $(\mathrm{DMF}-\mathrm{T}=0)$. The Community Periodontal Index (CPI), as proposed by the World Health Organization, was used to assess the periodontal condition of children with regard to the presence of gingival bleeding, calculus and periodontal pockets. ${ }^{12}$

The Social Vulnerability Index (SVI) was collected from public domain data (https://www.ivs.ipea.gov.br). The SVI is a result of the weighted calculation of sixteen social parameters extracted from the demographic census, divided into 3 domains (urban infrastructure, human capital, and wage and work). The SVI ranges from 0 to 1 ; extremely low values mean less vulnerability, while higher values represent 
higher vulnerability. Municipalities can be classified as having low $(\mathrm{SVI}<0.3)$, medium (between 0.3 and $0.4)$, high (between 0.4 and 0.5$)$ and very high $(>0.5)$ vulnerability. The SVI value for the state of São Paulo in 2015 was equal to 0.238 . HDI data were collected from a public domain information system (https://www.ibge.gov.br). The HDI is a United Nations indicator that considers three domains: wages, education and health. The HDI scale ranges from $0-1$, so higher values represent higher levels of human development. The HDI of the state of São Paulo is equal to 0.783 (https://cidades.ibge.gov.br/brasil/ $\mathrm{sp} /$ panorama). For the present study, SVI and HDI data were used as continuous (numerical) variables.

\section{Theoretical-conceptual model}

A theoretical conceptual model was used to guide statistical analysis (Figure 1). The dental caries experience (based on DMF-T) was considered the dependent variable. The independent variables were structured in a hierarchical model, defined by the ability of independent variables to interfere in the dependent variable (contextual variables $>$ individual variables> periodontal conditions).

\section{Statistical analysis}

Data were tabulated in a spreadsheet, and a descriptive analysis was performed to verify

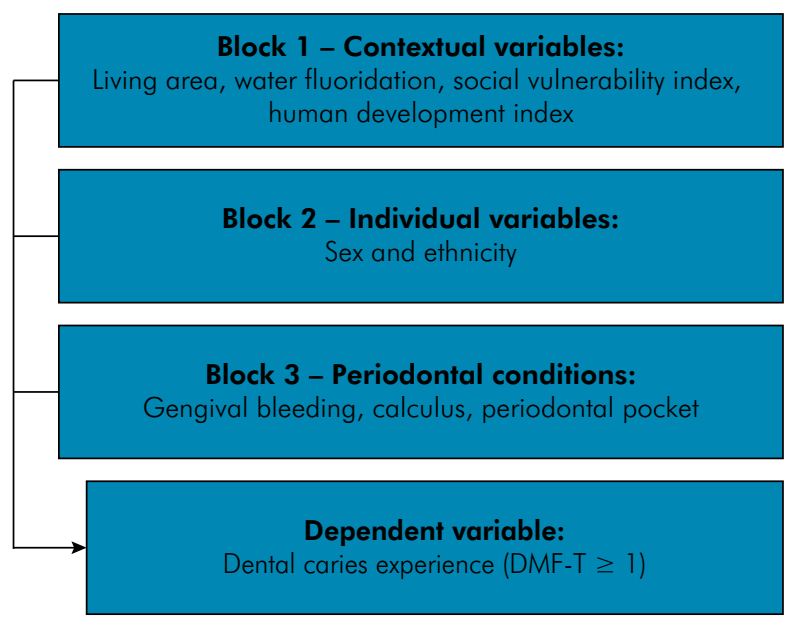

Figure 1. Conceptual theoretical model for the study of the association between caries experience in a population of 12-year-old children and independent variables subdivided into contextual, individual and periodontal variables. absolute and relative frequencies. Data were then transferred to the software IBM Statistical Package for the Social Sciences (IBM SPSS, v. 20, Chicago, USA) for appropriate statistical analysis. Data from 26,325 (96.4\%) individuals were included in the analysis. The missing data of $980(3.6 \%)$ individuals were lost due to a lack of information about one or more of the studied variables.

Initially, bivariate analyses were performed between the dependent and independent variables. For this study, two multivariate regression models were used to assess factors associated with dental caries experience among the 12-year-old population. First, a multivariate hierarchical logistic regression analysis was performed with the Hosmer-Lemeshow adjustment $(p>0.05)$. For this purpose, the dependent variable was dichotomized into two groups (no dental caries experience: DMF-T=0; with dental caries experience: DMF-T $\geq 1$ ). In addition, data were analyzed using multivariate Poisson regression analysis, in which the dependent variable (DMF-T) was included as a continuous variable. Models were adjusted by the backward stepwise (Wald) method. Odds ratios (ORs) were used as measures of association, with a confidence interval of $95 \%$.

\section{Results}

The results of this study showed that $57.6 \%$ of 12-year-old participants had experienced dental caries (DMF-T $\geq 1$ ). Descriptive analysis showed that dental caries experience was observed in $54.8 \%$ of urban children, $56.2 \%$ of those living in areas with fluoridated water, $31.1 \%$ of those living in areas of high social vulnerability (SVI $>0.22$ ) and $30.9 \%$ of those living in cities with low HDI (HDI < 0.745) (Table 1). In addition, $51.2 \%$ of the sample consisted of females, of whom $30.5 \%$ presented dental caries experience. Dental caries experience was observed in $22.8 \%$ of the nonwhite population and in children with gingival bleeding (12.7\%), calculus (3.3\%) and periodontal pockets $(0.1 \%)$ (Table 1$)$.

The results of hierarchical multivariate logistic regression analysis showed that nonwhite ethnicity $(\mathrm{OR}=1.113,95 \% \mathrm{CI}=1.085-1.142)$ and gingival bleeding $(\mathrm{OR}=1.204,95 \% \mathrm{CI}=1.166-1.243)$ 
Table 1. Distribution of dental caries experience among 12-year-old children $(n=27,295)$, according to contextual, individual and periodontal variables.

\begin{tabular}{|c|c|c|c|}
\hline \multirow{2}{*}{ Variables } & \multicolumn{2}{|c|}{ Caries experience } & \multirow{2}{*}{$p$-value $\left(x^{2}\right.$} \\
\hline & $D M F-T=0$ & DMF-T $\geq 1$ & \\
\hline \multicolumn{4}{|l|}{ Contextual variables } \\
\hline \multicolumn{4}{|l|}{ Region of residence } \\
\hline Urban & $11,011(40,4 \%)$ & $14,944(54.8 \%)$ & 0.018 \\
\hline Rural & $516(1.9 \%)$ & 803 (2.9\%) & \\
\hline \multicolumn{4}{|l|}{ Water fluoridation } \\
\hline Without fluoride & $256(0.9 \%)$ & $417(1.5 \%)$ & 0.023 \\
\hline Fluoridated water & $11,200(41.4 \%)$ & $15,204(56.2 \%)$ & \\
\hline \multicolumn{4}{|l|}{ SVI } \\
\hline Below median $(\leq 0.22)$ & $5770(21.1 \%)$ & $7260(26.6 \%)$ & $<0.001$ \\
\hline Above median (>0.22) & $5770(21.1 \%)$ & $8503(31.1 \%)$ & \\
\hline \multicolumn{4}{|l|}{$\mathrm{HDI}$} \\
\hline Below median $(>0.745)$ & 5867 (21.5\%) & $7340(26.9 \%)$ & $<0.001$ \\
\hline Above median $(\leq 0.745)$ & $5673(20.8 \%)$ & $8423(30.9 \%)$ & \\
\hline \multicolumn{4}{|l|}{ Individual variables } \\
\hline \multicolumn{4}{|l|}{ Sex } \\
\hline Male & $5899(21.6 \%)$ & $7441(27.3 \%)$ & $<0.001$ \\
\hline Female & $5638(20.7 \%)$ & $8317(30.5 \%)$ & \\
\hline \multicolumn{4}{|l|}{ Ethnicity } \\
\hline White & $7468(27.6 \%)$ & $9423(34.8 \%)$ & $<0.001$ \\
\hline Nonwhite & 3979 (14.7\%) & $6176(22.8 \%)$ & \\
\hline \multicolumn{4}{|l|}{ Periodontal variables } \\
\hline \multicolumn{4}{|l|}{ Gingival bleeding } \\
\hline No & $9470(35.3 \%)$ & $12,069(45.0 \%)$ & $<0.001$ \\
\hline Yes & $1886(7.0 \%)$ & $3411(12.7 \%)$ & \\
\hline \multicolumn{4}{|l|}{ Calculus } \\
\hline No & $10,784(40.2 \%)$ & $14,603(54.4 \%)$ & 0.024 \\
\hline Yes & $572(2.1 \%)$ & 877 (3.3\%) & \\
\hline \multicolumn{4}{|l|}{ Periodontal pocket } \\
\hline No & 11,335 (42.2\%) & $15,448(57.6 \%)$ & 0.691 \\
\hline Yes & $21(0.1 \%)$ & $32(0.1 \%)$ & \\
\hline
\end{tabular}

DMF-T: decayed, missing and filled teeth; SVI: Social Vulnerability Index, categorized by the median; HDI: Human Development Index, categorized by the median.

were associated with dental caries experience (Table 2). In addition, male children (OR $=0.920$, $95 \% \mathrm{CI}=0.898-0.943)$ and increased HDI (OR $=0.022$, $95 \% \mathrm{CI}=0.010-0.048)$ were associated with no dental caries experience (Table 2). Adjusted statistics for multivariate logistic regression analysis showed a Hosmer-Lemeshow test p-value of 0.656, which suggested a well-adjusted model.

Multivariate Poisson regression analysis showed that water fluoridation $(\mathrm{OR}=0.766$, $95 \% \mathrm{CI}=0.692-0.848)$ and $\mathrm{HDI}(\mathrm{OR}=0.040$,
$95 \% \mathrm{CI}=0.025-0.066)$ were associated with lower dental caries experience (Table 3 ). In addition, higher dental caries experience (greater DMF-T) was associated with female sex $(O R=1.164$, $95 \% \mathrm{CI}=1.129-1.201)$, nonwhite ethnicity $(\mathrm{OR}=1.154$, $95 \% \mathrm{CI}=1.119-1.191)$ and gingival bleeding $(\mathrm{OR}=1.255$, 95\%CI = 1.210-1.301) (Table 3). The adjusted statistics, using Poisson Multivariate regression, showed an omnibus test with a p-value $<0.0001$, meaning that the explained variance was statistically greater than the unexplained variance. 
Table 2. Non-adjusted and adjusted multivariate logistic regression model that assessed factors associated with the dental caries experience of 12-year-old children $(n=26,325)$.

\begin{tabular}{|c|c|c|c|c|c|c|c|}
\hline \multicolumn{8}{|l|}{ Non-adjusted model } \\
\hline \multirow{2}{*}{ Independent variables } & \multirow{2}{*}{ B } & \multirow{2}{*}{ S.E. } & \multirow{2}{*}{ Wald } & \multirow{2}{*}{$p$-value } & \multirow{2}{*}{ OR } & \multicolumn{2}{|c|}{$95 \% \mathrm{Cl}$} \\
\hline & & & & & & Lower & Upper \\
\hline \multicolumn{8}{|l|}{ Contextual variables } \\
\hline Region of residence (urban) & 0.031 & 0.030 & 1.048 & 0.306 & 1.031 & 0.972 & 1.094 \\
\hline Water fluoridation (yes) & 0.052 & 0.042 & 1.549 & 0.213 & 1.053 & 0.971 & 1.143 \\
\hline SVI (continuous) & 0.032 & 0.282 & 0.013 & 0.910 & 1.032 & 0.594 & 1.793 \\
\hline HDI (continuous) & -3.408 & 0.512 & 44.316 & $<0.001$ & 0.033 & 0.012 & 0.090 \\
\hline \multicolumn{8}{|l|}{ Individual variables } \\
\hline Sex (male) & -0.077 & 0.013 & 38.042 & $<0.001$ & 0.926 & .903 & .949 \\
\hline Ethnicity (nonwhite) & 0.112 & 0.013 & 74.761 & $<0.001$ & 1.119 & 1.091 & 1.148 \\
\hline \multicolumn{8}{|l|}{ Periodontal variables } \\
\hline Gingival bleeding (yes) & 0.185 & 0.016 & 126.783 & $<0.001$ & 1.203 & 1.165 & 1.243 \\
\hline Calculus (yes) & 0.005 & 0.029 & 0.035 & 0.852 & 1.005 & 0.951 & 1.063 \\
\hline \multicolumn{8}{|l|}{ Adjusted model } \\
\hline \multirow{2}{*}{ Independent variables } & \multirow{2}{*}{ B } & \multirow{2}{*}{ S.E. } & \multirow{2}{*}{ Wald } & \multirow{2}{*}{$p$-value } & \multirow{2}{*}{ OR } & \multicolumn{2}{|c|}{$95 \% \mathrm{Cl}$} \\
\hline & & & & & & Lower & Upper \\
\hline Water fluoridation (yes) & 0.038 & 0.041 & 0.856 & 0.355 & 1.039 & 0.958 & 1.127 \\
\hline HDI (continuous) & -3.824 & 0.406 & 88.657 & $<0.001$ & 0.022 & 0.010 & 0.048 \\
\hline Sex (male) & -0.083 & 0.013 & 43.864 & $<0.001$ & 0.920 & 0.898 & 0.943 \\
\hline Ethnicity (nonwhite) & 0.107 & 0.013 & 67.549 & $<0.001$ & 1.113 & 1.085 & 1.142 \\
\hline Gingival bleeding (yes) & 0.186 & 0.016 & 131.500 & $<0.001$ & 1.204 & 1.166 & 1.243 \\
\hline
\end{tabular}

SVI: Social Vulnerability Index; HDI: Human Development Index; B: regression coefficient; S.E.: standard error; OR: odds ratio; 95\%Cl: 95\% confidence interval.

\section{Discussion}

The results of this study show that contextual, individual and periodontal variables were associated with dental caries experience among 12-year-old children. Previous studies have investigated factors associated with dental caries among 12-year-old children, and this study showed that inequalities continued to be associated with the prevalence of dental caries. ${ }^{6,7,8,9,12,14}$ Data from this study must support policymakers to enable them to direct interventions towards reducing the prevalence of dental caries among children and the impact of dental caries on their oral health in adulthood.

Although the oral health of 12-year-old children has improved over the past few years, ${ }^{9}$ the factors associated with dental caries have not changed in the meantime. ${ }^{67,8,12,14}$ This finding illustrated that the prevalence of dental caries in children was markedly associated with social inequalities at different levels. Based on the foregoing discourse, further investments and public policies must be directed towards reducing the impact of social inequalities on health conditions. However, the economic crisis and austerity policies adopted worldwide have accentuated social inequalities and have also induced an impact on health outcomes. ${ }^{21,22}$

The social determinants of dental caries were still evident in this manuscript, in agreement with the findings observed in previous studies. ${ }^{6,78,9,12,14,23}$ Although this has been extensively discussed in the literature, no reduction in the gap between social inequalities and the expansion of access to fluoridated water has been observed. The data of the present study illustrated the most updated scenario, in which 12-year-old children are still impacted by inequalities at different levels.

No effect of the SVI on the prevalence of dental caries was observed in the present study. A previous study concluded that the SVI had no impact on 
Table 3. Non-adjusted and adjusted multivariate Poisson regression model that assessed factors associated with dental caries experience in 12-year-old children ( $\mathrm{n}=26,325)$.

\begin{tabular}{|c|c|c|c|c|c|c|c|}
\hline \multicolumn{8}{|l|}{ Non-adjusted model } \\
\hline \multirow{2}{*}{ Independent variables } & \multirow{2}{*}{$\mathrm{B}$} & \multirow{2}{*}{ S.E. } & \multirow{2}{*}{ Wald } & \multirow{2}{*}{$\mathrm{p}$-value } & \multirow{2}{*}{ OR } & \multicolumn{2}{|c|}{$95 \% \mathrm{Cl}$} \\
\hline & & & & & & Lower & Upper \\
\hline \multicolumn{8}{|l|}{ Contextual variables } \\
\hline Region of residence (rural) & $-0,067$ & 0,0374 & 3,213 & 0,073 & 0,935 & 0,869 & 1,006 \\
\hline Water fluoridation (yes) & $-0,303$ & 0,0517 & 34,274 & $<0.001$ & 0,739 & 0,667 & 0,817 \\
\hline SVI (continuous) & $-0,088$ & 0,1777 & 0,246 & 0,62 & 0,916 & 0,646 & 1,297 \\
\hline HDI (continuous) & $-3,181$ & 0,3226 & 97,22 & $<0.001$ & 0,042 & 0,022 & 0,078 \\
\hline \multicolumn{8}{|l|}{ Individual variables } \\
\hline Sex (female) & 0,145 & 0,0157 & 84,871 & $<0.001$ & 1,156 & 1,121 & 1,192 \\
\hline Ethnicity (nonwhite) & 0,151 & 0,016 & 89,458 & $<0.001$ & 1,163 & 1,127 & 1,2 \\
\hline \multicolumn{8}{|l|}{ Periodontal variables } \\
\hline Gingival bleeding (yes) & 0,224 & 0,0186 & 144,637 & $<0.001$ & 1,251 & 1,206 & 1,297 \\
\hline Calculus (yes) & 0,029 & 0,0331 & 0,785 & 0,376 & 1,03 & 0,965 & 1,099 \\
\hline \multicolumn{8}{|l|}{ Adjusted model } \\
\hline \multirow{2}{*}{ Independent variables } & \multirow{2}{*}{ B } & \multirow{2}{*}{ S.E. } & \multirow{2}{*}{ Wald } & \multirow{2}{*}{$p$-value } & \multirow{2}{*}{ OR } & \multicolumn{2}{|c|}{$95 \% \mathrm{Cl}$} \\
\hline & & & & & & Lower & Upper \\
\hline Living area (rural) & $-0,059$ & 0,037 & 2,558 & 0,11 & 0,942 & 0,876 & 1,013 \\
\hline Water fluoridation (yes) & $-0,266$ & 0,0518 & 26,374 & 0 & 0,766 & 0,692 & 0,848 \\
\hline HDI (continuous) & $-3,212$ & 0,2484 & 167,169 & $<0.001$ & 0,04 & 0,025 & 0,066 \\
\hline Sex (female) & 0,152 & 0,0157 & 94,543 & $<0.001$ & 1,164 & 1,129 & 1,201 \\
\hline Ethnicity (nonwhite) & 0,143 & 0,0159 & 80,883 & $<0.001$ & 1,154 & 1,119 & 1,191 \\
\hline Gingival bleeding (yes) & 0,227 & 0,0184 & 152,231 & $<0.001$ & 1,255 & 1,21 & 1,301 \\
\hline
\end{tabular}

SVI: Social Vulnerability Index; HDI: Human Development Index; B: regression coefficient; S.E.: standard error; OR: odds ratio; $95 \% \mathrm{Cl}$ : 95\% confidence interval.

the quality of life of adolescents in the state of São Paulo oral health survey. ${ }^{12}$ Although the effects of social vulnerability on clinical outcomes were not investigated in this previous study, the social determinants of dental caries were expected to show some influence of the SVI. The SVI was composed of sixteen indicators organized into 3 domains (urban infrastructure, human capital, and wage and work). Accordingly, the poorer and more vulnerable municipalities were expected to be associated with a higher level of caries experience. However, there was a mean significant difference of 0.003 in the municipal SVI between children with and without dental caries experience. Thus, the quantitative distribution of the municipal SVI may not impact the prevalence of dental caries among 12-year-old children.

Nevertheless, the effect of other contextual variables (the HDI and water fluoridation) was observed in the present study. Previous studies have demonstrated that water fluoridation was associated with lower dental caries experience ${ }^{15,23,24}$. In our study, the effect of water fluoridation was observed only within the multivariate Poisson regression. This illustrated that children who have access to fluoridated water have a lower number of teeth affected by dental caries; however, water fluoridation did not interfere with the prevalence of caries-free children. The majority of cities in the state of São Paulo have had fluoridated water for over 15 years, which determined that a significant portion of the population had access to the preventive effect of fluoride. Although the preventive effect of fluoride is recognized as being responsible for the lower severity of dental caries among the 12-year-old population, there are still municipalities that do not have access to fluoridated water. The water fluoridation law in Brazil dates back to 1974, and the Smiling Brazil Program offered financial support for fluoridation. 
Therefore, the reasons for not implementing water fluoridation are unknown or are based on political decisions and are not supported by the literature. Greater difficulty in the implementation of water fluoridation has been observed in less developed and poorer municipalities. ${ }^{14}$

With regard to the HDI, this study demonstrated that a higher prevalence of caries-free children and lower DMF-T were associated with municipalities with a higher Human Development Index. The higher level of dental caries experience in populations in less developed areas may be related to low purchasing power, low educational and socioeconomic levels and difficulty of access to health services., ${ }^{9,14}$ This scenario is clearly unequal, and policymakers should direct their actions towards reducing inequalities and promoting social justice. ${ }^{16,24}$ There is a need to direct health care towards less developed communities, in addition to investing in schooling and reducing social inequities.

The United Nations frequently uses the HDI to rank countries with regard to their development, since this index considers information relative to wages, education and health. Frequently, the living conditions of the population are a reflection of the contextual characteristics of municipalities, and this may also interfere with the health status. ${ }^{21}$ Previous studies have demonstrated that higher family and neighborhood wages were associated with lower dental caries prevalence among children. ${ }^{8,14,23}$ In addition, higher educational levels among parents were associated with a lower prevalence of dental caries. ${ }^{7,8}$ Thus, the socioeconomic status of families interferes with the prevalence and severity of dental caries among children.

A higher prevalence of dental caries among nonwhite children was also associated with social inequalities, and social exclusion was still observed in Brazil. The influence of skin color has previously been demonstrated. ${ }^{6,714,23}$ Although some affirmative policies on cash transfer and educational support have been implemented in Brazil to reduce social inequalities among nonwhite people, those related to skin color continue to influence the prevalence of dental caries among nonwhite children ${ }^{25}$. Therefore, public policies must be more efficient in improving the oral health of the less privileged and nonwhite child population.

The influence of sex on dental caries experience has also been demonstrated by other studies. ${ }^{6,7}$ The higher likelihood of dental caries experience among girls may be related to the early eruption of permanent teeth in the oral cavity and gender differences in perceptions of oral health, in addition to a greater commitment of parents to the oral health of girls. ${ }^{6,7,26}$ In addition, the higher level of dental caries experience among children could be explained by the fact that girls are more frequent users of dental services, ${ }^{26}$ which may also allow them to take greater advantage of receiving restorative procedures.

The findings of this study suggested that the presence of calculus and periodontal pockets were not associated with dental caries experience in 12-year-old children. However, gingival bleeding had an impact on the dental caries experience of 12-year-old children. Bleeding is periodontal evidence of biofilm accumulation, which may lead to a greater chance of developing dental caries. ${ }^{18}$ A higher level of gingival bleeding may be related to the hormonal changes that occur at this stage of puberty. ${ }^{27}$ It may also be related to other risk factors, such as inefficient oral hygiene, high sugar consumption and insufficient knowledge about oral health. ${ }^{28}$ The majority of these risk factors should also be recognized as being associated with a lower socioeconomic level, which may interfere with the higher rates of dental caries prevalence. ${ }^{28}$

It should be noted that gingival bleeding is an avoidable condition, controlled mainly by appropriate hygiene measures. The distribution of oral hygiene kits was part of the national oral health policy in Brazil (Smiling Brazil Program), which was extensively focused on schoolchildren. It is therefore recommended that preventive practices directed towards schoolchildren must not be abandoned. The distribution of oral hygiene kits has been discontinued over the past few years, and this will probably impact the most vulnerable children, since costs of oral health care products may impact the budgets of less privileged families. ${ }^{29}$

It is emphasized that the findings of this study are the results of a cross-sectional analysis. Therefore, 
the relationships of association demonstrated in this study should be interpreted with caution. Nevertheless, the data of this study were derived from a population-based sample, which allowed the data to have strong consistency. Although a multilevel analysis is considered a more robust statistical method, the hierarchical multivariate analyses presented in this study showed similar statistical significance of independent variables.

The most concerning finding highlighted in the present study was that social inequalities still interfere significantly with the prevalence of dental caries among children. Public health managers should therefore consider factors associated with the dental caries experience of 12-year-old children. Public policies directed towards reducing social inequalities and increasing access to health services among the less privileged population may contribute to reducing the risk of dental caries and consequently to reducing the loss of teeth among children. In addition, this may significantly impact health care costs, since dental caries are considered the most prevalent disease worldwide. ${ }^{30}$

\section{Conclusion}

Dental caries experience among 12-year-old children continues to be associated with social inequalities at different levels (contextual, individual, and biological). Policymakers should direct interventions towards reducing inequalities and the prevalence of dental caries among 12-year-old children.

\section{Acknowledgments}

This study was supported by the Fundação de Amparo a Pesquisa do Estado de São Paulo - FAPESP (Project Number 14/50109-1). We thank the National Council for Scientific and Technological Development (CNPq) and the Coordination for the Improvement of Higher Education Personnel (CAPES) for granting scholarships to ACMB (CNPq-130005) and IMB (CAPES-1757970), respectively.

\section{References}

1. Lauris JR, Bastos RS, Bastos JRM. Decline in dental caries among 12-year-old children in Brazil, 1980-2005. Int Dent J. 2012 Dec;62(6):308-14. https://doi.org/10.1111/i.1875-595x.2012.00124.x

2. Gimenez T, Bispo BA, Souza DP, Viganó ME, Wanderley MT, Mendes fm, et al. does the decline in caries prevalence of latin american and caribbean children continue in the New Century? Evidence from systematic review with meta-analysis. PLoS One. 2016 Oct;11(10):e0164903. https://doi.org/10.1371/journal.pone.0164903

3. Aguiar VR, Pattussi MP, Celeste RK. The role of municipal public policies in oral health socioeconomic inequalities in Brazil: a multilevel study. Community Dent Oral Epidemiol. 2018 Jun;46(3):245-50. https://doi.org/10.1111/cdoe.12356

4. Kassebaum NJ, Bernabé E, Dahiya M, Bhandari B, Murray CJ, Marcenes W. Global burden of untreated caries: a systematic review and metaregression. J Dent Res. 2015 May;94(5):650-8. https://doi.org/10.1177/0022034515573272

5. Pucca Jr GA, Gabriel M, Araujo ME, Almeida FC. Ten years of a national oral health policy in Brazil: innovation, boldness, and numerous challenges. J Dent Res. 2015 Oct;94(10):1333-7. https://doi.org/10.1177/0022034515599979

6. Antunes JL, Peres MA, Mello TRC, Waldman EA. Multilevel assessment of determinants of dental caries experience in Brazil. Community Dent Oral Epidemiol. 2006 Apr;34(2):146-52. https://doi.org/10.1111/j.1600-0528.2006.00274.x

7. Oliveira LB, Moreira RS, Reis SC, Freire MC. Dental caries in 12-year-old schoolchildren: multilevel analysis of individual and school environment factors in Goiânia. Rev Bras Epidemiol. 2015 Jul-Sep;18(3):642-54. https://doi.org/10.1590/1980-5497201500030010

8. Engelmann JL, Tomazoni F, Oliveira MD, Ardenghi TM. Association between dental caries and socioeconomic factors in Schoolchildren: a multilevel analysis. Braz Dent J. 2016 Jan-Feb;27(1):72-8. https://doi.org/10.1590/0103-6440201600435

9. Roncalli AG, Sheiham A, Tsakos G, Araújo-Souza GC, Watt RG. Social factors associated with the decline in caries in Brazilian children between 1996 and 2010. Caries Res. 2016;50(6):551-9. https://doi.org/10.1159/000442899

10. Richmond S, Chestnutt I, Shennan J, Brown R. The relationship of medical and dental factors to perceived general and dental health. Community Dent Oral Epidemiol. 2007 Apr;35(2):89-97. https://doi.org/10.1111/j.1600-0528.2007.00296.x

11. Frazão P. Epidemiology of dental caries: when structure and context matter. Braz Oral Res. 2012;26(spe1 Suppl 1):108-14. https://doi.org/10.1590/S1806-83242012000700016 
Dental caries experience and associated factors in 12-year-old-children: a population based-study

12. Cunha IP, Pereira AC, Frias AC, Vieira V, Meneghim MC, Batista MJ, et al. Social vulnerability and factors associated with oral impact on daily performance among adolescents. Health Qual Life Outcomes. 2017 Aug;15(1):173. https://doi.org/10.1186/s12955-017-0746-1

13. Martins MT, Sardenberg F, Vale MP, Paiva SM, Pordeus IA. Dental caries and social factors: impact on quality of life in Brazilian children. Braz Oral Res. 2015;29(1):S1806-83242015000100310. https://doi.org/10.1590/1807-3107BOR-2015.vol29.0133

14. Freire MC, Reis SC, Figueiredo N, Peres KG, Moreira RS, Antunes JL. [Individual and contextual determinants of dental caries in Brazilian 12-year-olds in 2010]. Rev Saude Publica. 2013 Dec;47 Suppl 3:40-9. Portuguese. https://doi.org/10.1590/S0034-8910.2013047004322

15. Narvai PC, Frazão P, Roncalli AG, Antunes JL. [Dental caries in Brazil: decline, polarization, inequality and social exclusion]. Rev Panam Salud Publica. 2006 Jun;19(6):385-93. Portuguese. https://doi.org/10.1590/S1020-49892006000600004

16. Drummond AM, Ferreira EF, Gomes VE, Marcenes W. Inequality of experience of dental caries between different ethnic groups of Brazilians aged 15 to 19 years. PLoS One. 2015 Dec;10(12):e0145553. https://doi.org/10.1371/journal.pone.0145553

17. Bulgareli JV, Faria ET, Cortellazzi KL, Guerra LM, Meneghim MC, Ambrosano GM, et al. Factors influencing the impact of oral health on the daily activities of adolescents, adults and older adults. Rev Saude Publica. 2018;52:44. https://doi.org/10.11606/S1518-8787.2018052000042

18. Zhang S, Xu B, Liu J, Lo EC, Chu CH. Dental and periodontal status of 12-year-old Dai school children in Yunnan Province, China: a cross-sectional study. BMC Oral Health. 2015 Oct;15(1):117. https://doi.org/10.1186/s12903-015-0106-7

19. Passos-Soares JS, Santos LP, Cruz SS, Trindade SC, Cerqueira EM, Santos KO, et al. The impact of caries in combination with periodontitis on oral health-related quality of life in Bahia, Brazil. J Periodontol. 2018 Dec;89(12):1407-17. https://doi.org/10.1002/JPER.18-0047

20. Pereira AC, Vladen V, Frias AC. Oral health state survey: final report. 1st ed. Àguas de São Pedro: Livronovo; 2016.

21. Stuckler D, Reeves A, Loopstra R, Karanikolos M, McKee M. Austerity and health: the impact in the UK and Europe. Eur J Public Health. 2017;27(suppl_4):18-21. https://doi.org/10.1093/eurpub/ckx167

22. Lopez-Valcarcel BG, Barber P. Economic crisis, austerity policies, health and fairness: lessons learned in Spain. Appl Health Econ Health Policy. 2017 Feb;15(1):13-21. https://doi.org/10.1007/s40258-016-0263-0

23. Ardenghi TM, Piovesan C, Antunes JL. [Inequalities in untreated dental caries prevalence in preschool children in Brazil]. Rev Saude Publica. 2013 Dec;47 Suppl 3:129-37. https://doi.org/10.1590/S0034-8910.2013047004352

24. Gabardo MC, Silva WJ, Moysés ST, Moysés SJ. Water fluoridation as a marker for sociodental inequalities. Community Dent Oral Epidemiol. 2008 Apr;36(2):103-7. https://doi.org/10.1111/j.1600-0528.2007.00381.x

25. Calvasina P, O'Campo P, Pontes MM, Oliveira JB, Vieira-Meyer AP. The association of the Bolsa Familia Program with children's oral health in Brazil. BMC Public Health. 2018 Oct;18(1):1186. https://doi.org/10.1186/s12889-018-6084-3

26. Antunes JL, Junqueira SR, Frazão P, Bispo CM, Pegoretti T, Narvai PC. City-level gender differentials in the prevalence of dental caries and restorative dental treatment. Health Place. 2003 Sep;9(3):231-9. https://doi.org/10.1016/S1353-8292(02)00055-2

27. Elias-Boneta AR, Ramirez K, Rivas-Tumanyan S, Murillo M, Toro MJ. Prevalence of gingivitis and calculus in 12-year-old Puerto Ricans: a cross-sectional study. BMC Oral Health. 2018 Jan;18(1):13. https://doi.org/10.1186/s12903-017-0471-5

28. Pereira SM, Pardi V, Cortellazzi KL, Ambrosano GM, Vettorazzi CA, Ferraz SF, et al. Geographic information system and multilevel analysis: gingival status among 12-year-old schoolchildren in São Paulo, Brazil. Rev Panam Salud Publica. 2014 Feb;35(2):136-43.

29. Kelly SE, Binkley CJ, Neace WP, Gale BS. Barriers to care-seeking for children's oral health among low-income caregivers. Am J Public Health. 2005 Aug;95(8):1345-51. https://doi.org/10.2105/AJPH.2004.045286

30. Peres MA, Macpherson LM, Weyant RJ, Daly B, Venturelli R, Mathur MR, et al. Oral diseases: a global public health challenge. Lancet. 2019 Jul;394(10194):249-60. https://doi.org/10.1016/S0140-6736(19)31146-8 